Mens

revue d'histoire intellectuelle de l'Amérique française

Louis-Georges Harvey. Le Printemps de l'Amérique française.

Américanité, anticolonialisme et républicanisme dans le discours politique québécois, 1805-1837. Montréal, Boréal, 2005. 296 p.

\title{
Renaud Séguin
}

Volume 8, numéro 2, printemps 2008

URI : https://id.erudit.org/iderudit/1022838ar

DOI : https://doi.org/10.7202/1022838ar

Aller au sommaire du numéro

Éditeur(s)

Centre de recherche en civilisation canadienne-française

ISSN

1492-8647 (imprimé)

1927-9299 (numérique)

Découvrir la revue

Citer ce compte rendu

Séguin, R. (2008). Compte rendu de [Louis-Georges Harvey. Le Printemps de l'Amérique française. Américanité, anticolonialisme et républicanisme dans le discours politique québécois, 1805-1837. Montréal, Boréal, 2005. 296 p.] Mens, 8(2), 397-401. https://doi.org/10.7202/1022838ar 
Louis-Georges Harvey. Le Printemps de l'Amérique française. Américanité, anticolonialisme et républicanisme dans le discours politique québécois, 1805-1837. Montréal, Boréal, 2005. 296 p.

Depuis quelques années, le concept d'américanité a été l'objet de plusieurs analyses historiques et sociologiques dans le milieu intellectuel québécois. L'ouvrage de Louis-Georges Harvey sur la sphère politique bas-canadienne se révèle une contribution importante à ce débat. En s'intéressant aux perceptions des États-Unis véhiculées dans des journaux, brochures, documents officiels et correspondances des politiciens de l'époque, il aborde le républicanisme et l'anti-colonialisme des élites politiques canadiennes, puis patriotes. Inspiré par les travaux de Gérard Bouchard, l'auteur décrit « l'évolution du discours politique bas-canadien comme la mise en place d'un projet de société qui visait à préparer, dans un avenir plus ou moins rapproché, la mutation de la colonie en un État indépendant » (p. 16). Harvey profite de l'occasion pour remettre en question le libéralisme que plusieurs ont attribué aux patriotes, insistant plutôt sur l'importance du lexique emprunté à l'humanisme civique.

Le premier chapitre de l'essai est ainsi consacré à l'étude des racines gréco-romaines de la pensée de Papineau, de ses contemporains et de ses prédécesseurs. À l'instar de plusieurs acteurs politiques du XVIII ${ }^{e}$ siècle anglais et de leurs homologues états-uniens, les patriotes sont fortement influencés par l'idéal de l'humanisme civique. Ce dernier insiste sur l'importance du rôle politique des citoyens indépendants dans la lutte contre la dégénération provoquée par la concentration de la richesse et les abus de pouvoir qui en découlent. Les tenants du «Country Party », les révolutionnaires de 1776, les républicains de Jefferson, les démocrates de Jackson et les réformistes bas-canadiens formulent tous leurs conceptions poli- 
tiques selon cet idéal pétri par la morale classique. Le petit propriétaire terrien y devient, particulièrement en Amérique, le modèle de la vertu politique garant de la pérennité de la république, elle-même la forme de gouvernement idéale au Nouveau Monde. Aux citoyens égaux et vertueux s'opposent les forces des aristocraties traditionnelles et financières qui tentent d'imposer à la société leur gouvernement corrupteur. Harvey soutient que les attaques des patriotes contre les bureaucrates, leurs alliés vice-royaux et finalement la métropole londonienne doivent être interprétées dans cet optique plutôt que dans celui d'un quelconque libéralisme. C'est à l'aune de leur conception de l'humanisme civique que les écrivains et journalistes qu'étudie Harvey jugent les progrès de la république voisine.

L'auteur décrit le début du XIX ${ }^{c}$ siècle comme l'époque d'un « repli ». Contraints à exprimer leurs griefs dans des termes rigoureusement loyaux, les écrivains, essayistes et journalistes liés au parti canadien dépeignent alors la société étatsunienne comme celle des pires excès mercantiles et de la pire des corruptions. La conjoncture internationale de l'époque et les mesures répressives des autorités coloniales qui en découlent les forcent à épouser les préjugés britanniques envers les républiques du moment. L'accalmie qui suit la guerre de 1812 accorde une plus grande liberté de parole. Dès 1817, les discours des réformistes canadiens à propos des sociétés américaine et britannique se transforment. Le débat autour du projet d'union de 1822 occupe cependant une importance majeure dans l'argumentaire d'Harvey. Les Canadiens y perdent leurs illusions sur la bonne volonté des autorités londoniennes à leur égard. Progressivement, les discours concernant la nation états-unienne se font plus flatteurs, cette dernière se présente comme un exemple de vertu civique. Les référents européens sont abandonnés au profit d'arguments qu'Harvey lie à l'américanité. Ainsi, la Révolution de 1776, autrefois 
honnie, est réhabilitée. La composante républicaine inspirée par la rhétorique jeffersonienne, elle-même alimentée par l'humanisme civique, occupe une part de plus en plus visible dans le discours des réformistes canadiens. Ils en viennent à concevoir la lutte qui les oppose au gouverneur et aux bureaucrates comme un affrontement contre la corruption que représente «l'alliance de 'l'argent' avec l'Exécutif » (p. 133). L'omniprésence du référent états-unien dans l'argumentaire de Papineau et de ses alliés porte leurs adversaires à insister sur les failles de la société américaine telles que l'esclavage et l'intolérance religieuse. Dans les années 1830, les politiciens patriotes, exacerbés par l'attitude des autorités impériales, en viennent à envisager pour le Bas-Canada un destin semblable à celui des treize colonies. Lors des événements de 1837-1838, la révolution de 1776 inspire directement la rhétorique et les stratégies des leaders patriotes. Harvey déplore que la vision de Lord Durham faisant du mouvement d'émancipation canadien une banale révolte ethnocentriste de la majorité francophone fut reprise par «les historiens ». Il n'identifie cependant pas à qui il réfère.

Le sujet auquel se consacre l'essai de Louis-Georges Harvey est d'un intérêt indéniable. L'impact des événements qui ont lieu dans la république états-unienne et des idées qui y circulent dans la sphère politique bas-canadienne mérite d'être étudié avec soin. Harvey expose par son étude tout le potentiel de ce sujet et ce qu'il permet de révéler sur d'autres aspects du passé québécois. Il démontre l'importance des idées républicaines chez les réformistes patriotes et, de manière un peu moins convaincante, chez leurs prédécesseurs du parti canadien tout en apportant une réflexion intéressante sur l'humanisme civique, ses origines et son influence dans le monde atlantique. Il est toutefois étonnant que malgré le vaste corpus retenu, l'auteur n'ait pas jugé bon d'étudier le Vindicator, journal anglophone pro-patriote. Cette publication aurait sans 
doute fourni des éléments supplémentaires soutenant la thèse de l'auteur quant à l'aspect inclusif de l'idéologie patriote. De plus, Harvey aurait peut-être dû apporter quelques nuances supplémentaires à son analyse du républicanisme et de l'humanisme civique aux États-Unis. Quoiqu'il mentionne certaines des ambivalences de la politique jacksonienne, Harvey sous-estime la rupture qui existe entre cette dernière et celle de Jefferson comme l'a, entre autres, souligné Gordon S. Wood.

Certaines de ses conclusions soulèvent aussi quelques objections. À titre d'exemple, mentionnons que les professions de foi loyalistes des Canadiens d'avant 1812 sont peutêtre plus sincères que ne semble le suggérer l'auteur. De même, certains pourraient remettre en question l'ampleur de la rupture idéologique avec les référents européens avant 1830. Ces éléments demeurent cependant de simples questions d'interprétation qui n'enlèvent rien à la valeur inestimable de l'étude. À l'opposé, lorsque l'auteur quitte le XIX' siècle pour tenter d'étendre son propos à la situation politique actuelle, il perd en pertinence ce qu'il gagne en polémique. À la fin du chapitre quatre, Harvey conclut spontanément : «les adversaires du mouvement [patriote] ont opposé la peur à la raison dans la défense d'un statu quo colonial devenu insoutenable. C'est là une tactique, on le reconnaîtra, qui sera reprise à plus d'une occasion par les tenants du statu quo au Québec. » (p. 191) De même, il n'hésite pas à utiliser l'expression "canadian » pour décrire le fédéralisme actuel, et ce, sans justifier l'utilisation de ce vocable. Ces déclarations à l'emporte-pièce détonnent avec la démarche fouillée d'Harvey sur le monde politique bas-canadien. Heureusement, elles sont peu nombreuses.

Malgré ces bémols, ce Printemps de l'Amérique française demeure une lecture essentielle pour qui s'intéresse à la sphère politique québécoise voire même occidentale. Il resitue l'histoire intellectuelle du Bas-Canada dans son contexte interna- 
tional tout en démontrant, une fois de plus, la nécessité de $s$ 'inspirer des historiographies étrangères pour perfectionner nos connaissances du passé national. Il reste à souhaiter que le républicanisme bas-canadien francophone et anglophone fera l'objet d'autres études exhaustives.

Renaud Séguin Département d'histoire University of Toronto

\section{Katherine Fierlbeck. Political Thought in Canada:} An Intellectual History. Peterborough, Broadview Press, 2006. 178 p.

Katherine Fierlbeck, dir. The Development of Political Thought in Canada: An Anthology. Peterborough, Broadview Press, 2005. 324 p.

Les titres trompeurs doivent être évités. Par exemple, l'ouvrage de G.P. de T. Glazebrook History of Canadian Political Thought (1966) n'avait rien d'une histoire de la pensée politique au Canada. Il s'agissait plutôt d'un survol quelque peu idiosyncratique de l'histoire politique canadienne. À la décharge de l'auteur, peu de choses concernant la pensée politique canadienne avaient été publiées en 1966. Quarante ans plus tard, ce n'est plus le cas. Le temps est ainsi venu de produire une synthèse. Malgré son titre, l'ouvrage de Katherine Fierlbeck Political Thought in Canada: An Intellectual History n'est pas cette synthèse. Il ne porte pas sur la pensée politique et n'est pas une histoire intellectuelle.

S'adressant principalement aux étudiantes et aux étudiants de premier cycle en science politique, cet ouvrage " will hopefully give them a clearer understanding of why modern 